\title{
Improvement of Physicochemical Characteristics of Monoepoxide Linoleic Acid Ring Opening for Biolubricant Base Oil
}

\author{
Jumat Salimon, Nadia Salih, and Bashar Mudhaffar Abdullah \\ School of Chemical Sciences and Food Technology, Faculty of Science and Technology, Universiti Kebangsaan Malaysia, \\ Selangor, 43600 Bangi, Malaysia \\ Correspondence should be addressed to Jumat Salimon, jumat@ukm.my
}

Received 13 June 2011; Revised 21 July 2011; Accepted 21 July 2011

Academic Editor: Rumiana Koynova

Copyright () 2011 Jumat Salimon et al. This is an open access article distributed under the Creative Commons Attribution License, which permits unrestricted use, distribution, and reproduction in any medium, provided the original work is properly cited.

For environmental reasons, a new class of environmentally acceptable and renewable biolubricant based on vegetable oils is available. In this study, oxirane ring opening reaction of monoepoxide linoleic acid (MEOA) was done by nucleophilic addition of oleic acid (OA) with using p-toluene sulfonic acid (PTSA) as a catalyst for synthesis of 9(12)-hydroxy-10(13)-oleoxy-12(9)octadecanoic acid (HYOOA) and the physicochemical properties of the resulted HYOOA are reported to be used as biolubricant base oils. Optimum conditions of the experiment using D-optimal design to obtain high yield\% of HYOOA and lowest OOC $\%$ were predicted at OA/MEOA ratio of $0.30: 1(\mathrm{w} / \mathrm{w})$, PTSA/MEOA ratio of $0.50: 1(\mathrm{w} / \mathrm{w})$, reaction temperature at $110^{\circ} \mathrm{C}$, and reaction time at $4.5 \mathrm{~h}$. The results showed that an increase in the chain length of the midchain ester resulted in the decrease of pour point $(\mathrm{PP})-51^{\circ} \mathrm{C}$, increase of viscosity index (VI) up to 153 , and improvement in oxidative stability (OT) to $180.94^{\circ} \mathrm{C}$.

\section{Introduction}

The use of renewable biolubricant derivatives from vegetable oils and its fatty acids, to obtain industrial products, is of increasing importance [1]. The development of new biolubricant and environmentally benign pathways, which can lead to new value-added products, has still a high potential [2].

Vegetable-oils-based materials have inferior oxidation stability and low-temperature operability when compared to petroleum products. Chemical modification of the unsaturation fatty acids can provide products with improved oxidation stability and low-temperature properties. Examples from the studies, though certainly not exhaustive, include acylation, metathesis, hydroxylation, oxidative cleavage, carboxylation, and epoxidation [3].

A variety of chemical modifications of vegetable oils and fatty acids are possible, and one of the most commonly used is the oxirane ring opening reaction [4]. The epoxide can react with different nucleophiles to produce alcohols, diols, alkoxyalcohols, hydroxy esters, N-hydroxyalkylamides, mercaptoalcohols, aminoalcohols, and so forth [2]. Amongst these classes of products, hydroxy esters find application as biolubricants, polyurethane foams, or casting resins. The physicochemical properties of biolubricants derived from hydroxy esters can be modified using different carboxylic acids [3]. The oxirane ring opening takes place through cleavage the carbon oxygen bonds. It can be initiated by either electrophiles or nucleophiles, or catalyzed by either acids or bases. The acid catalyzed of an epoxide is a useful procedure for preparing hydroxy ester compounds [5].

In this study, report the oxirane ring opening reaction of monoepoxide linoleic acid (MEOA) by the nucleophilic addition of oleic acid (OA) in the presence of solid acid catalyst such as p-toluene sulfonic acid (PTSA) to prepare 9,12hydroxy-10,13-oleioxy-12-octadecanoic acid (HYOOA). The effects of different ratio of OA/MEOA, different ratio of PTSA/MEOA, different reaction temperature, and different reaction time are analyzed in using $\mathrm{D}$-optimal design. The experimental conditions and catalysts used were different from those previously used, leading to better selectivity towards the hydroxyl ester under mild working conditions. Other important issues like the physicochemical properties of the products are also reported here. 


\section{Methodology}

2.1. Experimental Procedure. The oxirane ring opening reaction was carried out using oleic acid (OA) and $p$-toluene sulfonic acid (PTSA) as catalyst to prepare 9,12-hydroxy-10,13oleioxy-12-octadecanoic acid (HYOOA) [6]. Table 1 shows the different OA/MEOA ratio, different PTSA/MEOA ratio, different reaction temperature, and different reaction time using D-Optimal design. Factors (variables) such as ratio OA/MEOA $\left(\mathrm{g} / \mathrm{g}, X_{1}\right)$, PTSA/MEOA $\left(\mathrm{g} / \mathrm{g}, X_{2}\right)$, reaction temperature $\left({ }^{\circ} \mathrm{C}, X_{3}\right)$, and reaction time $\left(\mathrm{h}, X_{4}\right)$ were performed under the same experimental conditions. MEOA (1.55g) and ratio PTSA/MEOA $(0.2: 1-0.5: 1 \mathrm{w} / \mathrm{w})$ were dissolved in toluene $(10 \mathrm{~mL})$ in a $250-\mathrm{mL}$ three-neck flask equipped with a cooler, dropping funnel, and thermometer. The mixture was kept at $50^{\circ} \mathrm{C}$. OA/MEOA ratio $(0.30: 1-0.60: 1 \mathrm{w} / \mathrm{w})$ was added during $1.5 \mathrm{~h}$ in order to keep the reaction mixture temperature under $70-80^{\circ} \mathrm{C}$. The reaction mixture was subsequently heated to different temperatures $90-110^{\circ} \mathrm{C}$ and refluxed at different times 3-6 h at this temperature range. After reaction termination, the heating was stopped and the mixture was left to stand overnight at ambient temperature. The mixture was washed with the water, the organic layer was dried over anhydrous sodium sulphate, and the solvent was removed using the vacuum evaporator. The oxirane ring content (OOC $\%$ ), yield $\%$, and iodine value (IV mg/g) were measured. The FTIR and ${ }^{13} \mathrm{C},{ }^{1} \mathrm{H}$ NMR were analysed, and the physicochemical properties of the product were studied.

2.2. Experimental Design and Statistical Analysis. To explore the effect of the operation variables on the response in the region of investigation, a D-optimal design was performed. Ratio of OA/MEOA $\left(\mathrm{g} / \mathrm{g}, X_{1}\right)$, ratio of PTSA/MEOA $(\mathrm{g} / \mathrm{g}$, $\left.X_{2}\right)$, reaction temperature $\left({ }^{\circ} \mathrm{C}, X_{3}\right)$, and reaction time $\left(\mathrm{h}, X_{4}\right)$ were selected as independent variables. The range of values and coded levels of the variables are given in Table 1. A polynomial equation was used to predict the response as a function of independent variables and their interactions. In this work, the number of independent variables is four, and, therefore, the response for the quadratic polynomials becomes

$$
Y=\beta_{0}+\sum \beta_{i} x_{i}+\sum \beta_{i i} x_{i}^{2}+\sum \sum \beta_{i j} x_{i} x_{j}
$$

where $\beta_{0}, \beta_{i}, \beta_{i i}$, and $\beta_{i j}$ are constant, linear, square, and interaction regression coefficient terms, respectively, and $x_{i}$ and $x_{j}$ are independent variables. The Minitab software version 14 (Minitab Inc., USA) was used for multiple regression analysis, analysis of variance (ANOVA), and analysis of ridge maximum of data in the response surface regression (RSREG) procedure. The goodness of fit of the model was evaluated by the coefficient of determination $R^{2}$ and its statistical significance that was checked by the $F$-test.

\subsection{Physicochemical Characteristics}

(a) FTIR. FTIR spectra were recorded neat on a Thermo Nicolet Nexus 470 FTIR system (Madison, Wis) with a Smart ARK accessory containing a $45 \mathrm{Ze}$ Se trough in a scanning
TABLE 1: Independent variables and their levels for D-optimal design of the oxirane ring opening reaction.

\begin{tabular}{lcccc}
\hline \multirow{2}{*}{ Independent variables } & & \multicolumn{3}{c}{ Variable levels } \\
& & -1 & 0 & +1 \\
\hline (1) OA/MEOA (w/w) & $X_{1}$ & 0.30 & 0.45 & 0.60 \\
$(2)$ PTSA/MEOA $(w / w)$ & $X_{2}$ & 0.2 & 0.35 & 0.5 \\
$(3)$ Temperature $\left({ }^{\circ} \mathrm{C}\right)$ & $X_{3}$ & 90 & 100 & 110 \\
(4) Time $(\mathrm{h})$ & $X_{4}$ & 3 & 4.5 & 6 \\
\hline
\end{tabular}

range of $650-4000 \mathrm{~cm}^{-1}$ for 32 scans at a spectral resolution of $4 \mathrm{~cm}^{-1}$ [6].

(b) ${ }^{13} \mathrm{C}$ and ${ }^{1} \mathrm{H}$ NMR. ${ }^{13} \mathrm{C}$ and ${ }^{1} \mathrm{H}$ NMR spectra were recorded using a JEOL JNM-ECP 400 spectrometer operating at a frequency of 400.13 and $100.77 \mathrm{MHz}$, respectively, using a 5 -mm broadband inverse Z-gradient probe in DMSO-d6 (Cambridge Isotope Laboratories, Andover, Mass) as solvent. Each spectrum was Fourier-transformed, phase-corrected, and integrated using MestRe-C 2.3a (Magnetic Resonance Companion, Santiago de Compostela, Spain) software [6].

(c) Pour Point. Pour point (PP) value was measured according to the ASTM D5949 method [6] using a phase Technology Analyzer, Model PSA-70S (Hammersmith Gate, Richmond, BC, Canada). For a greater degree of accuracy, PP measurements were done with a resolution of $1^{\circ} \mathrm{C}$ instead of the specified $3^{\circ} \mathrm{C}$ increment.

(d) Flash Point. Flash point (FP) determination was run according to the American National Standard Method using a Tag Closed Tester (ASTM D 56-79) [6].

(e) Viscosity Index. Viscosity index (VI) is an arbitrary measure for the change of kinematic viscosity with temperature. Automated multirange viscometer tubes HV M472 obtained from Walter Herzog (Germany) were used to measure viscosity. Measurements were run in a Temp-Trol (Precision Scientific, Chicago, Ill, USA) viscometer bath set at 40.0 and $100.0^{\circ} \mathrm{C}$. The viscosity and viscosity index were calculated using ASTM method ASTM D 2270-93 [6].

(f) Oxidative Stability. Pressurized DSC (PDSC) experiments were accomplished using a DSC 2910 thermal analyzer from TA Instruments (Newcastle, Del) [6]. Typically, a 2-lL sample, resulting in a film thickness of $<1 \mathrm{~mm}$, was placed in an aluminum pan hermetically sealed with a pinhole lid and oxidized in the presence of dry air (Gateway Airgas, St. Louis, $\mathrm{Mo}$ ), which was pressurized in the module at a constant pressure of $1378.95 \mathrm{kPa}(200 \mathrm{psi})$. A $10^{\circ} \mathrm{C} \mathrm{min}^{-1}$ heating rate from 50 to $350^{\circ} \mathrm{C}$ was used during each experiment. The oxidation onset $\left(\mathrm{OT},{ }^{\circ} \mathrm{C}\right)$ was calculated from a plot of heat flow $(\mathrm{W} / \mathrm{g})$ versus temperature for each experiment. 


\section{Results and Discussion}

3.1. Effect of Process Parameters and Statistical Analysis. Many nucleophilic reagents are known to add to an oxirane ring, resulting in ring opening [6]. These ring opening reactions could result in branching at the oxirane ring opening (earlier sites of unsaturation in LA). The appropriate branching groups would interfere with the formation of macrocrystalline structures during low-temperature applications and would provide enhanced fluidity to vegetable oils. TAGs that are hydrogenated to eliminate polyunsaturation such as LA will solidify at room temperature. For this reason, it is important that there should be at least one unsaturation site available for a functionalization that will generate two branching points on the chain. The ester branching groups produce from oxirane ring opening base esterification reaction are effective for attaining the desired molecular spacing. A chain length ester (saturated and unsaturated) has been observed to deliver the most desired physicochemical properties for some oils [7]. These modified vegetable oils with chain branching are reported to have superior performance of the physicochemical properties and are promising as biolubricant [8].

The nucleophilic attack by fatty acid molecules such as oleic acid $(\mathrm{OA})$ on the oxirane ring of MEOA in the presence of PTSA resulted in the ring-opened products 9,12-hydroxy10,13-oleioxy-12-octadecanoic acid (HYOOA), as shown in Figure 1. In the first pathway mechanism, the acid reacts with the epoxide group to produce a protonated epoxide and finally alcohol compound form by nucleophilic substitution reaction. OA acts like nucleophiles during the acid-catalyzed epoxy ring opening reaction. This modification proposes that for one oxirane ring present in the MEOA, one ester and one hydroxyl functional groups will generate in the molecule.

Optimisation study of the oxirane ring-opening-based esterification reaction using $\mathrm{D}$-optimal design took place in the presence of OA with using PTSA as a catalyst. The design is used to obtain 25 design points within the whole range of four factors for experiments. The designs and the response OOC\% $(Y)$ are given in Table 2 with measuring the yield\% and IV $\mathrm{mg} / \mathrm{g}$ for the lowest OOC\% product. To see the impact on the oxirane ring opening by $\mathrm{OA}$ reaction, different ratio of OA/MEOA $\left(\mathrm{g} / \mathrm{g}, X_{1}\right)$, different ratio of PTSA/MEOA (g/g, $\left.X_{2}\right)$, different reaction temperature $\left({ }^{\circ} \mathrm{C}, X_{3}\right)$, and different reaction time $\left(\mathrm{h}, X_{4}\right)$ were evaluated Table 2.

Table 2 illustrates the OOC\% effect related to the OA, PTSA, reaction temperature, and reaction time. As expected, at high temperature, $110^{\circ} \mathrm{C}$, the OOC $\%$ shows a great reduction $0.05 \%$ compared with temperatures of 90 and $100^{\circ} \mathrm{C}$. This abrupt reduction on OOC\% percent by high temperature $\left(110^{\circ} \mathrm{C}\right)$ shows a high increment on yield $84.61 \%$ and iodine value $134.82 \mathrm{mg} / \mathrm{g}$ compared with initial iodine value $\left(\mathrm{IV}^{\circ}\right) 66.65 \mathrm{mg} / \mathrm{g}$. In light of these changes, other experiments optimisations were discontinued. As described in the mechanism, most of the oxirane ring groups are opened and consequently were converted into ester bonds in the molecule with hydroxyl group. At lower temperatures, fairly low oxirane ring reduction $(3.80 \%)$ was observed at $90^{\circ} \mathrm{C}$ for $4.5 \mathrm{~h}$ of reaction compared with $110^{\circ} \mathrm{C}$ for $4.5 \mathrm{~h}$. At $100^{\circ} \mathrm{C}$,
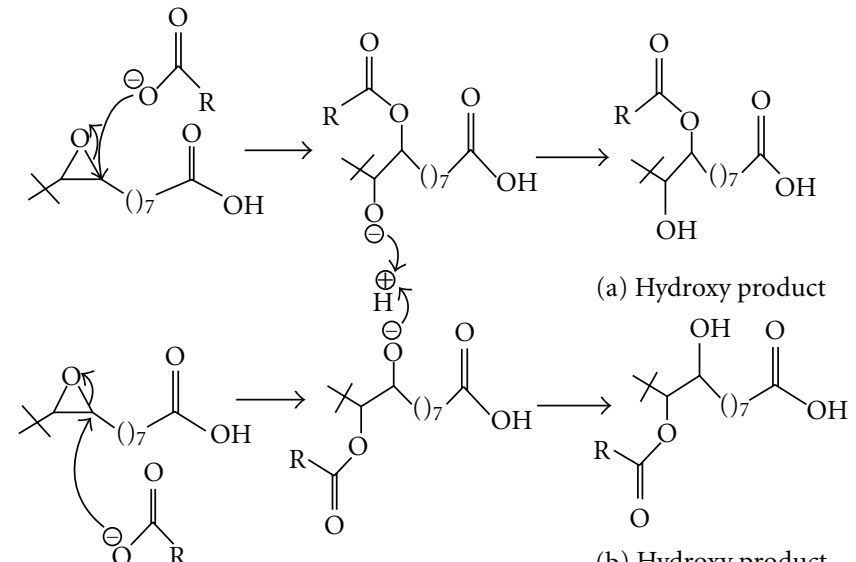

(b) Hydroxy product

Figure 1: Mechanism for the MEOA ring opening to afford ring opening product, 10 or 13-hydroxy (a); 9 or 12-hydroxy (b).

the OOC\% shows a smooth reduction during the reaction Table 2.

The quadratic regression coefficients obtained by employing a least squares method technique to predict quadratic polynomial models for the OOC\% ( $Y$ ) of HYOOA are given in Table 3. The OOC\% response of HYOOA $(Y)$ shows that the linear term of PTSA/MEOA ratio $\left(X_{2}\right)$ and quadratic terms of PTSA/MEOA ratio $\left(X_{22}\right)$ were significant $(P<0.05)$. The intercept of the reaction was highly significant $(P<$ $0.01)$.

The lack of fit $F$-value for all the responses showed that the lack of fit is not significant $(P>0.05)$ relative to the pure error. This indicates that all the models predicted for the responses were adequate. Regression models for data on responses $Y$ were significant $(P<0.05)$ with satisfactory $R^{2}$. However $R^{2}$ for $Y$ was (0.87), although the model was significant. Table 4 summarizes the analysis of variance (ANOVA) of all the responses of this study.

From the experimental design in Table 1, experimental results in Table 2 and (2) developed a second-order polynomial equation (in coded units) that could relate OOC\% of HYOOA to the parameters study. The following quadratic model was explained in (2):

$$
\begin{aligned}
Y= & +1.63-0.31 X_{1}-0.55 X_{2}-0.11 X_{3}-0.064 X_{4}+0.16 X_{1}^{2} \\
& +1.18 X_{2}^{2}-0.078 X_{3}^{2}-1.01 X_{4}^{2}+0.13 X_{1} X_{2}+0.14 X_{1} X_{3} \\
& -0.22 X_{1} X_{4}-0.23 X_{2} X_{3}+1.02 X_{2} X_{4}-0.017 X_{3} X_{4} .
\end{aligned}
$$

Significant interaction variables in the fitted models (Table 3 ) were chosen as the axes (OA/MEOA ratio; $X_{1}$, PTSA/MEOA ratio; $X_{2}$, reaction temperature; $X_{3}$ and reaction time; $X_{4}$ ) for the response surface plots. The relationships between independent and dependent variables are shown in the three-dimensional representation as response surfaces. In a contour plot, curves of equal response values are drawn on a plane whose coordinates represent the levels of the independent factors. Each contour represents a specific 
TABLE 2: D-optimal design arrangement and OOC \% response of HYOOA.

\begin{tabular}{|c|c|c|c|c|c|}
\hline \multirow{2}{*}{$\begin{array}{l}\text { Run } \\
\text { Number }\end{array}$} & \multicolumn{4}{|c|}{ Coded independent variable levels } & \multirow{2}{*}{$\begin{array}{c}\text { Response } \\
\text { OOC }^{\mathrm{d}} \\
(\%, Y)\end{array}$} \\
\hline & $\begin{array}{c}\mathrm{OA}^{\mathrm{a}} / \mathrm{MEOA}^{\mathrm{b}} \\
\left(\mathrm{w} / \mathrm{w}, X_{1}\right)\end{array}$ & $\begin{array}{c}\mathrm{PTSA}^{\mathrm{c}} / \mathrm{MEOA} \\
\quad\left(\mathrm{w} / \mathrm{w}, X_{2}\right)\end{array}$ & $\begin{array}{c}\text { Temperature } \\
\quad\left({ }^{\circ} \mathrm{C}, X_{3}\right)\end{array}$ & $\begin{array}{l}\text { Time } \\
\left(h, X_{4}\right)\end{array}$ & \\
\hline 1 & 0.60 & 0.20 & 110 & 4.5 & 2.60 \\
\hline 2 & 0.60 & 0.50 & 110 & 6 & 0.90 \\
\hline 3 & 0.30 & 0.20 & 90 & 4.5 & 3.80 \\
\hline 4 & 0.30 & 0.50 & 90 & 6 & 3.20 \\
\hline 5 & 0.30 & 0.20 & 110 & 3 & 3.40 \\
\hline 6 & 0.30 & 0.50 & 90 & 3 & 3.10 \\
\hline 7 & 0.45 & 0.50 & 100 & 4.5 & 2.70 \\
\hline 8 & 0.60 & 0.50 & 90 & 4.5 & 2.40 \\
\hline 9 & 0.30 & 0.35 & 100 & 4.5 & 2.10 \\
\hline 10 & 0.30 & 0.50 & 100 & 3 & 1.80 \\
\hline 11 & 0.30 & 0.20 & 100 & 6 & 1.50 \\
\hline 12 & 0.30 & 0.50 & 90 & 4.5 & 2.90 \\
\hline 13 & 0.45 & 0.20 & 100 & 4.5 & 3.05 \\
\hline 14 & 0.30 & 0.20 & 90 & 3 & 3.50 \\
\hline 15 & 0.30 & 0.35 & 110 & 6 & 0.60 \\
\hline 16 & 0.60 & 0.50 & 110 & 3 & 0.80 \\
\hline 17 & 0.45 & 0.20 & 110 & 6 & 0.40 \\
\hline 18 & 0.60 & 0.50 & 110 & 3 & 0.30 \\
\hline 19 & 0.60 & 0.20 & 90 & 3 & 2.95 \\
\hline 20 & 0.45 & 0.35 & 100 & 3 & 1.40 \\
\hline 21 & 0.45 & 0.35 & 100 & 5.25 & 0.20 \\
\hline 22 & 0.60 & 0.20 & 100 & 6 & 0.90 \\
\hline 23 & 0.60 & 0.20 & 90 & 6 & 0.70 \\
\hline 24 & 0.30 & 0.50 & 110 & 4.5 & 0.05 \\
\hline 25 & 0.60 & 0.35 & 100 & 4.5 & 0.60 \\
\hline
\end{tabular}

Notes: oleic acid (a); 9(12)-10(13)-monoepoxy 12(9)-octadecanoic acid (b); p-toluene sulfonic acid (c); oxirane oxygen content (d).

value for the height of the surface above the plane defined for combination of the levels of the factors. Therefore, different surface height values enable one to focus attention on the levels of the factors at which changes in the surface height occur [9].

Figure 2 are the Design-Expert plots for the response $(Y)$. In the oxirane ring opening reaction of HYOOA, performing the technique using high ratio of PTSA/MEOA would give the desired OOC\% of HYOOA. The relationships between the parameters and oxirane ring opening of HYOOA were linear or almost linear. Lowest OOC\% could be obtained by using high ratio of PTSA/MEOA at high reaction temperature, otherwise; other literatures have used lower PTSA such as [6]. Experimental variables should be carefully controlled in order to reduce the OOC\% of interest with reasonable yield $\%$.

Optimum conditions of the experiment to obtain high yield $\%$ of $\mathrm{HYOOA}$ and lowest OOC $\%$ were predicted at ratio of OA/MEOA of $0.30: 1(\mathrm{w} / \mathrm{w})$, ratio of PTSA/MEOA of $0.50: 1(\mathrm{w} / \mathrm{w})$, reaction temperature $110^{\circ} \mathrm{C}$, and $4.5 \mathrm{~h}$ of reaction time. At this condition, the OOC of HYOOA was $0.05 \%$, yield was $84.61 \%$, and IV was $134.82 \mathrm{mg} / \mathrm{g}$. The ob- served value was reasonably close to the predicted value as shown in Figure 3.

3.2. FTIR Analysis of HYOOA. The spectrum from the FTIR analysis displays several absorption peaks as shown in Figure 4. The main peaks and their assignment to functional groups are given in Table 5. FTIR peaks of HYOOA indicated disappearance of absorption band at $820 \mathrm{~cm}^{-1}$ which belong to the oxirane ring, hence, appear in MEOA. For the ester carbonyl functional groups $\mathrm{C}=\mathrm{O}$ of $\mathrm{HYOOA}$ at $1741 \mathrm{~cm}^{-1}$ and the carboxylic carbonyl vibration functional group at $1711 \mathrm{~cm}^{-1}$ which showed the same absorption band in MEOA at $1711 \mathrm{~cm}^{-1}$. FTIR peaks at 2925 to $2855 \mathrm{~cm}^{-1}$ indicated the $\mathrm{CH}_{2}$ and $\mathrm{CH}_{3}$ scissoring of MEOA and HYOOA.

The FTIR spectroscopy analysis of MEOA and HYOOA indicated the presence of peak at $3003-3008 \mathrm{~cm}^{-1}$ which belongs to the double bond $\mathrm{C}=\mathrm{C}$ (stretching aliphatic) while at $3413 \mathrm{~cm}^{-1}$ belong to $\mathrm{OH}$ stretching of HYOOA. The peaks at 1176 and $1117 \mathrm{~cm}^{-1}$ of HYOOA are referred to as (C-O) stretching ester. FTIR spectrum also showed absorption bands at $723 \mathrm{~cm}^{-1}$ for $(\mathrm{C}-\mathrm{H})$ group vibration. A similar 
TABLE 3: Regression coefficients of the predicted quadratic polynomial model for response variables of the OOC\% of HYOOA.

\begin{tabular}{ccccc}
\hline Variables & $\begin{array}{c}\text { Coefficients }(\beta), \\
\text { OOC\% }(Y)\end{array}$ & $T$ & $P$ & Notability \\
\hline Intercept & 1.63 & 5.19 & 0.0064 & $* * *$ \\
Linear & & & & \\
$X_{1}$ & -0.31 & 1.76 & 0.2143 & \\
$X_{2}$ & -0.55 & 5.73 & 0.0378 & $* *$ \\
$X_{3}$ & -0.11 & 0.23 & 0.6395 & \\
$X_{4}$ & -0.064 & $7.548 E-$ & 0.9325 & \\
Quadratic & & 003 & & \\
$X_{11}$ & 0.16 & & & \\
$X_{22}$ & 1.18 & 0.19 & 0.6699 & \\
$X_{33}$ & -0.078 & 8.1 & 0.0172 & $* *$ \\
$X_{44}$ & -1.01 & 0.65 & 0.4377 & \\
Interaction & & 1.47 & 0.2537 & \\
$X_{12}$ & 0.13 & & & \\
$X_{13}$ & 0.14 & 0.51 & 0.4912 & \\
$X_{14}$ & -0.22 & 2.05 & 0.1830 & \\
$X_{23}$ & -0.23 & 0.40 & 0.5423 & \\
$X_{24}$ & 1.02 & 5.99 & 0.0344 & \\
$X_{34}$ & -0.017 & 8.22 & 0.0168 & \\
$R^{2}$ & 0.87 & 003 & 0.9289 & \\
\hline
\end{tabular}

Notes: $X_{1}=$ OA/MEOA ratio; $X_{2}=$ PTSA/MEOA ratio; $X_{3}=$ reaction temperature; $X_{4}=$ reaction time, ${ }^{* *} P<0.05 ;{ }^{* * *} P<0.01 . T$ : $F$-test value. See Table 2 for a description of the abbreviations.

TABLE 4: Analysis of variance, showing the effect of the variables as linear, square and interactions on the response OOC $\%$ of HYOOA $(Y)$ of the D-optimal design.

\begin{tabular}{lccccc}
\hline Source & $D f$ & Sum of squares & Mean square & $F$ value & $P$ \\
\hline Mean & 1 & 85.75 & 85.75 & & \\
Linear & 4 & 19.89 & 4.97 & 5.76 & 0.0030 \\
2FI & 6 & 8.48 & 1.41 & 2.25 & 0.0987 \\
Quadratic & 4 & 4.28 & 1.07 & 2.38 & 0.1214 \\
Lack-of-fit & 10 & 4.50 & 0.45 & & \\
Pure error & 25 & 122.90 & 4.92 & & \\
\hline
\end{tabular}

observation has been reported for the FTIR spectrum of oxirane ring opening of epoxide oleic acid [6].

\section{3. ${ }^{13} \mathrm{C}$ and ${ }^{1} \mathrm{H}$ NMR Analysis of HYOOA}

(a) ${ }^{13} \mathrm{CNMR}$ Analysis. Figures 5(a) and 5(b) indicate the ${ }^{13} \mathrm{C}$ NMR spectrum of MEOA and HYOOA, respectively. The ${ }^{13} \mathrm{C}$ spectroscopy shows the main signals assignment of MEOA and HYOOA as shown in Table 6. The signals at 179.32 and $178.11 \mathrm{ppm}$ refer to the carbon atom of the carbonyl group (carboxylic acid) for MEOA and HYOOA, respectively, while $174.1 \mathrm{ppm}$ has appeared in HYOOA which refers to ester group.

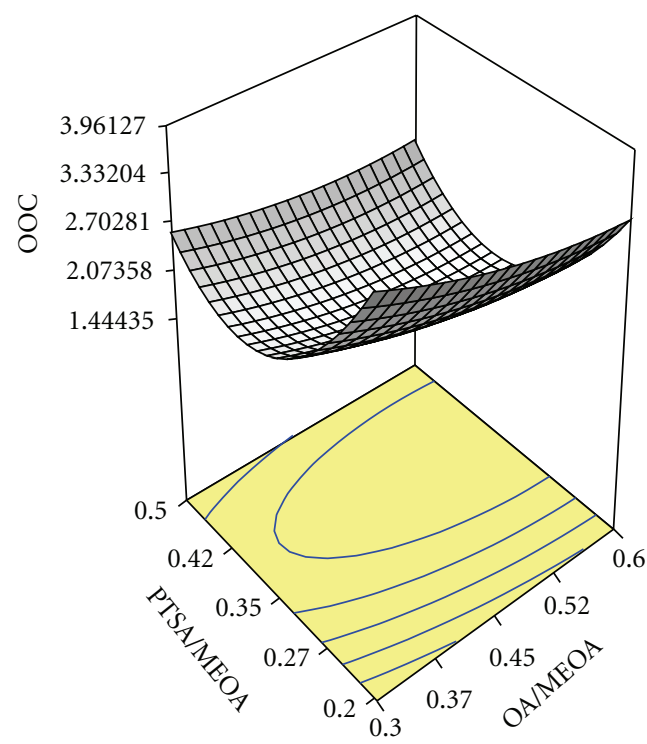

(a)

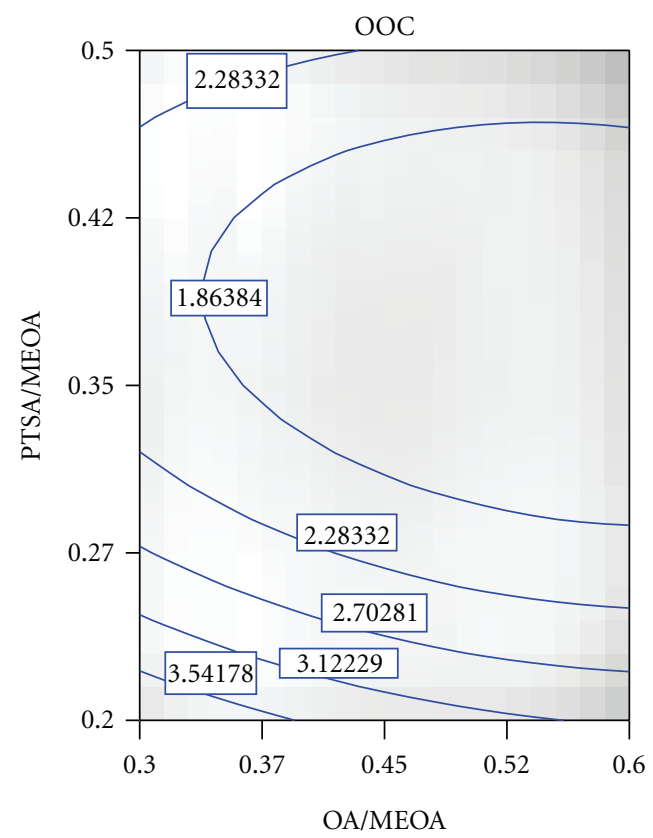

(b)

Figure 2: Response surface (a) and contour plots (b) for the effect of the OA/MEOA ratio $\left(X_{1}, \mathrm{w} / \mathrm{w}\right)$ and PTSA/MEOA ratio $\left(X_{2}, \mathrm{w} / \mathrm{w}\right)$ on the OOC\% of HYOOA.

The signals at 127.90 to $130.57 \mathrm{ppm}$ refer to the unsaturated carbon atoms (olefin carbons) for both MEOA and HYOOA. Figure 5(b) can be confirmed disappearance of oxirane ring which has appeared in MEOA at 54.59-57.29 and appearance $\mathrm{OH}$ alcohol in HYOOA at about $64.41 \mathrm{ppm}$. The other distinctive signals were aliphatic carbons HYOOA at about $25.76-34.38 \mathrm{ppm}$ and are common for these types of compounds which belong to the methylene carbon atoms of MEOA and HYOOA [6].

(b) ${ }^{1} \mathrm{H}$ NMR Analysis. ${ }^{1} \mathrm{H}$ NMR spectroscopy shows the main signals assignments of MEOA and HYOOA as shown 


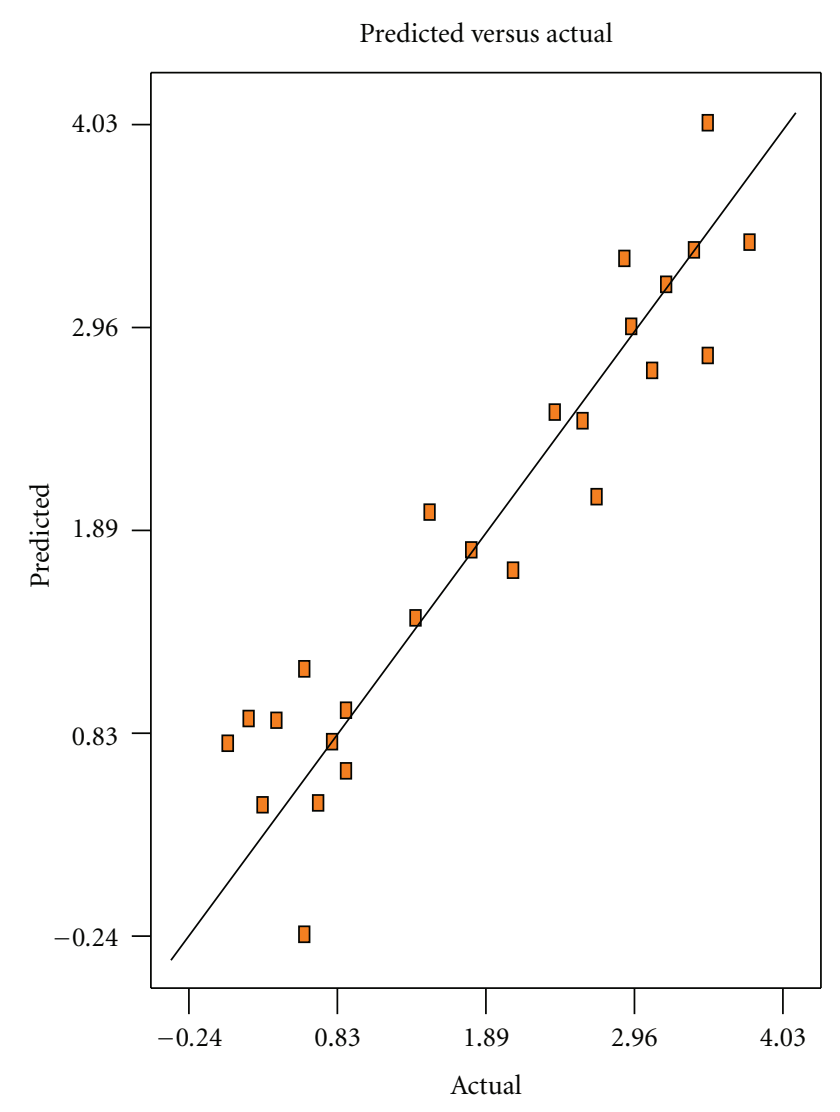

FIgUre 3: Predicated versus actual plot of $Y$ (HYOOA).

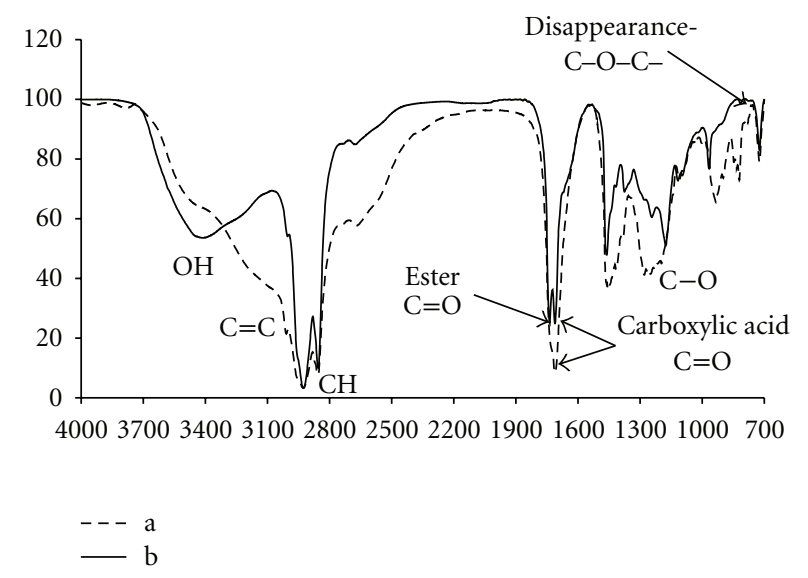

FIGURE 4: FTIR spectrum of the MEOA (a) and HYOOA (b).

in Table 7. The ${ }^{1} \mathrm{H}$ NMR spectra for the products HYOOA showed disappearance of the ring opening $(-\mathrm{CH}-\mathrm{O}-\mathrm{CH}-)$ in range of 2.92-3.12 ppm which referred to the MEOA Figure 6. The distinguishable peaks appeared in HYOOA$\mathrm{CH}-\mathrm{OH}$ at $3.62 \mathrm{ppm}$ while $-\mathrm{CHOCOR}$ at $4.06 \mathrm{ppm}$ which did not appeared in MEOA (Figures 6(a) and 6(b)).

The signals at $0.82-0.84 \mathrm{ppm}$ referred to the methylene group $\left(-\mathrm{CH}_{3}\right)$ of HYOOA which also appear in MEOA next to the terminal methyl $\left(-\mathrm{CH}_{2}\right)$ at $1.23-2.06 \mathrm{ppm}$ of HYOOA.

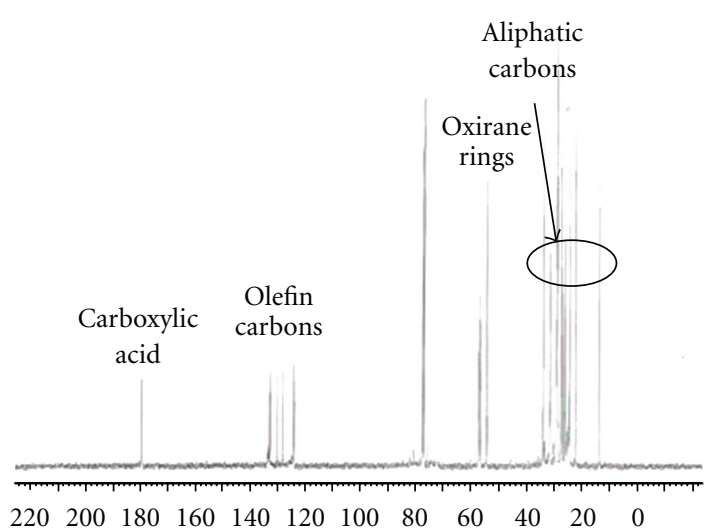

(a)

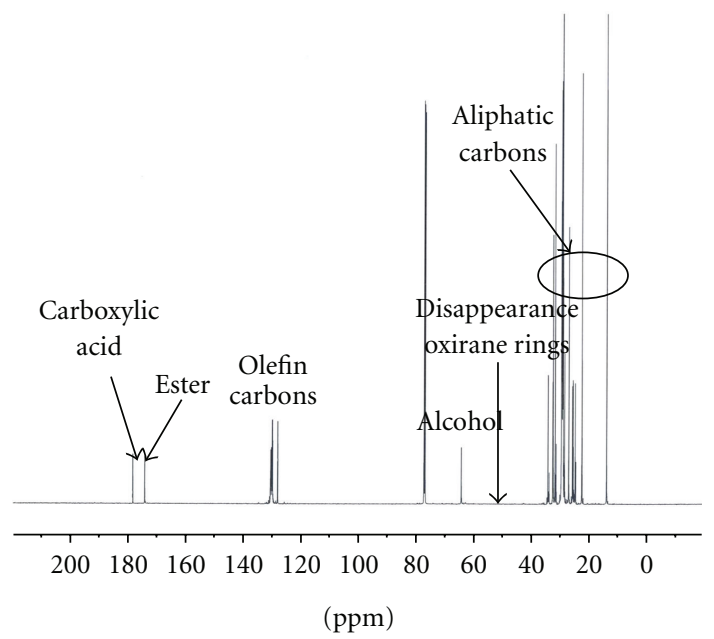

(b)

Figure 5: ${ }^{13} \mathrm{C}$ NMR spectrum of MEOA (a) and HYOOA (b).

The other distinctive signals were methine at about 2.26$2.33 \mathrm{ppm}$, which are common for these types of compounds [10]. However, the methane proton signals $(-\mathrm{CH}=\mathrm{CH}-)$ was shifted upfield at about 5.31-5.40 ppm of HYOOA.

3.4. Physicochemical Properties. Physicochemical properties of HYOOA compound are summarized in Table 8, an effective way to introduce branching on the fatty acid (FA) chain. The branched products have significantly improved the pour point (PP), flash point (FP), viscosity index (VI), and higher oxidative stability (OT) comparing with MEOA and another study such as [6].

This step of reaction is used to improve the low-temperature behavior (PP) of fatty acids by opening the oxirane ring by using $\mathrm{OA}$. Oxirane ring opening of HYOOA improves the $\mathrm{PP}$ at $-51^{\circ} \mathrm{C}$ significantly comparing with MEOA at $-41^{\circ} \mathrm{C}$ and HYBODA at $-43^{\circ} \mathrm{C}$ [6]. Attachment of OA to produce HYOOA was the most effective way to decrease the PP to -51 (Table 8). It can be assumed that the presence of a large branching point on the fatty acid ester creates a steric barrier around the individual molecules and inhibits crystallization, resulting in lower PP [11]. Table 8 has also 


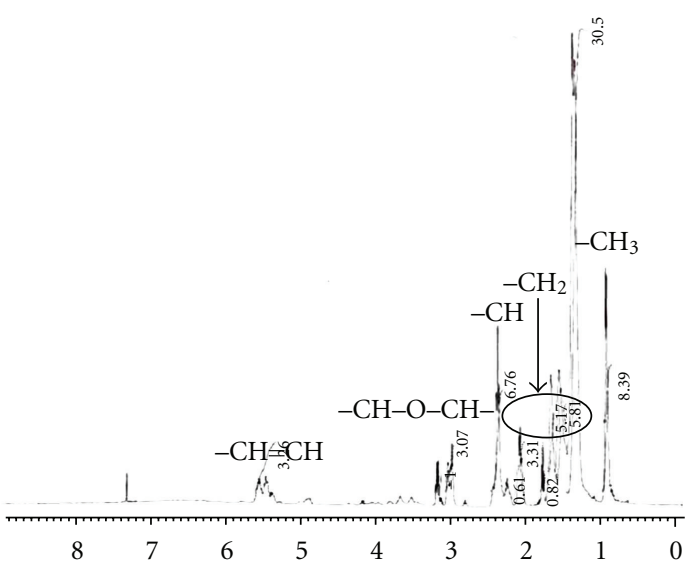

(a)

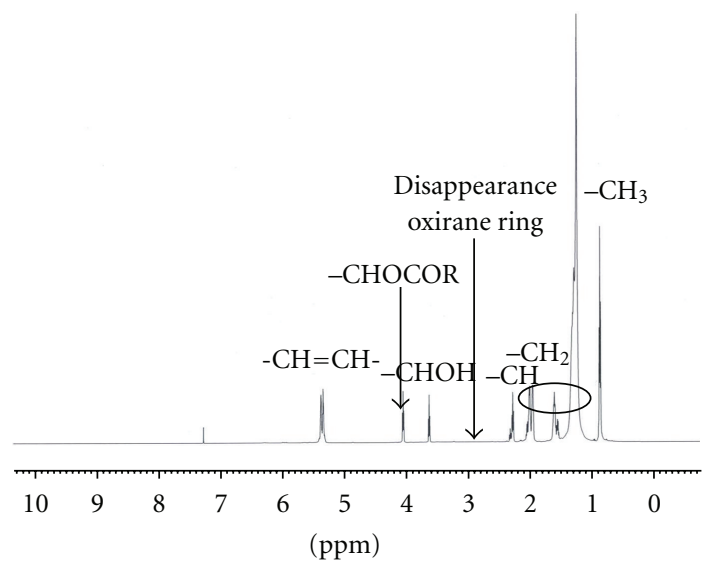

(b)

Figure 6: ${ }^{1} \mathrm{H}$ NMR spectrum of MEOA (a) and HYOOA (b).

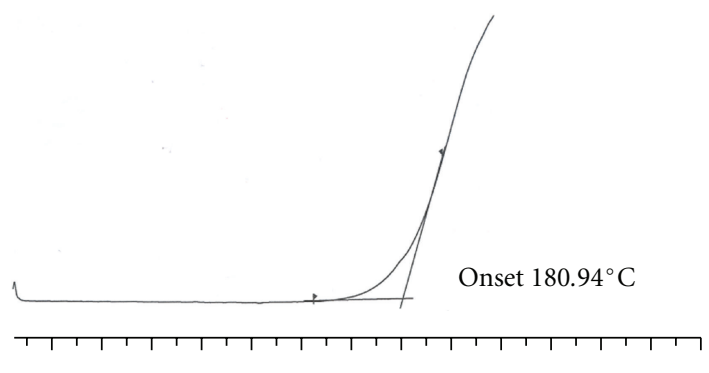

$40 \quad 60 \quad 80100120140160180200220240260280$

$\left({ }^{\circ} \mathrm{C}\right)$

Figure 7: Differential scanning calorimetry oxidation stability curve of HYOOA.

shown the improvement in FP of HYOOA which increased to $251^{\circ} \mathrm{C}$ comparing with $128^{\circ} \mathrm{C}$ of MEOA and $232^{\circ} \mathrm{C}$ of HYBODA [6], in which the result agrees with the various international standards.

The best oils (with the highest VI) will not vary much in viscosity over such a temperature range and therefore will perform well throughout. In oxirane ring opening, increased viscosity index (VI) up to 153 of HYOOA larger than MEOA
TABLE 5: The main wavelengths in the FTIR functional groups of MEOA and HYOOA.

\begin{tabular}{|c|c|c|}
\hline $\begin{array}{l}\text { Wavelength } \\
\text { of MEOA }^{\text {a }}\end{array}$ & $\begin{array}{l}\text { Wavelength } \\
\text { of } \mathrm{HYOOA}^{\mathrm{b}}\end{array}$ & Functional group \\
\hline- & 3003 & OH stretching (alcohol) \\
\hline 3009 & 3003 & $\mathrm{C}=\mathrm{C}$ bending vibration (aliphatic) \\
\hline 2927,2856 & 2925,2855 & $\mathrm{C}-\mathrm{H}$ stretching vibration (aliphatic) \\
\hline - & 1737 & $\mathrm{C}=\mathrm{O}$ stretching vibration (ester) \\
\hline 1711 & 1711 & $\begin{array}{l}\mathrm{C}=\mathrm{O} \text { stretching vibration } \\
\text { (carboxylic acid) }\end{array}$ \\
\hline - & 1461 & $\begin{array}{l}\text { C-H scissoring and bending for } \\
\text { methylene group }\end{array}$ \\
\hline - & 1176,1117 & $\mathrm{C}-\mathrm{O}$ stretching vibration (ester) \\
\hline 1279,1262 & 1279 & $\begin{array}{l}\text { C-O stretching asymmetric } \\
\text { (carboxylic acid) }\end{array}$ \\
\hline 934 & 934 & $\begin{array}{l}\mathrm{C}-\mathrm{O} \text { bending vibration } \\
\text { (carboxylic acid) }\end{array}$ \\
\hline 967 & 967 & $\mathrm{C}-\mathrm{H}$ bending vibration (alkene) \\
\hline 820 & - & $\mathrm{C}-\mathrm{O}-\mathrm{C}$ oxirane ring \\
\hline 723 & 723 & C-H group vibration (aliphatic) \\
\hline
\end{tabular}

Notes: Monoepoxide linoleic acid (a); 9,12-Hydroxy-10,13-oleioxy-12,9octadecanoic acid (b).

TABLE 6: The main signals present in ${ }^{13} \mathrm{C}$ NMR functional groups of MEOA and HYOOA.

\begin{tabular}{lcl}
\hline$\delta(\mathrm{ppm})$ of $\mathrm{MEOA}^{\mathrm{a}}$ & $\delta(\mathrm{ppm})$ of $\mathrm{HYOOA}^{\mathrm{b}}$ & Assignment \\
\hline $22.69-34.15$ & $25.76-34.38$ & Aliphatic carbons \\
$54.59-57.29$ & - & $(\triangle)$ Epoxide groups \\
- & 64.41 & $-\mathrm{OH}$ alcohol \\
$124.02-132.89$ & $127.90-130.57$ & $-\mathrm{CH}=\mathrm{CH}-$ olefinic \\
& 174.01 & $\mathrm{C}=\mathrm{O}$ ester \\
\hline & 178.11 & $\mathrm{C}=\mathrm{O}$ carboxylic acid \\
\hline
\end{tabular}

Notes: monoepoxide linoleic acid (a); 9,12-Hydroxy-10,13-oleioxy-12,9octadecanoic acid (b).

TABLE 7: The main signals present in ${ }^{1} \mathrm{H}$ NMR functional groups of MEOA and HYOOA.

\begin{tabular}{lcl}
\hline$\delta(\mathrm{ppm})$ of $\mathrm{MEOA}^{\mathrm{a}}$ & $\delta(\mathrm{ppm})$ of $\mathrm{HYOOA}^{\mathrm{b}}$ & Assignment \\
\hline $0.86-0.88$ & $0.82-0.84$ & $-\mathrm{CH}_{3}$ \\
$1.29-2.03$ & $1.23-2.06$ & $-\mathrm{CH}_{2}$ \\
$2.29-2.33$ & $2.26-2.33$ & $-\mathrm{CH}$ \\
$2.92-3.12$ & - & $-\mathrm{CH}-\mathrm{O}-\mathrm{CH}-$ \\
- & 3.62 & $-\mathrm{CHOH}$ \\
- & 4.06 & $-\mathrm{CHOCOR}$ \\
$5.38-5.49$ & $5.31-5.40$ & $-\mathrm{CH}=\mathrm{CH}-$
\end{tabular}

Notes: monoepoxide linoleic acid (a); 9,12-Hydroxy-10,13-oleioxy-12,9octadecanoic acid (b).

at 130.8 and HYBODA at 123 (Table 8), which, its result of their higher molar weight, and especially the altered structure of their molecules [11]. 
TABle 8: Physicochemical properties of MEOA and HYOOA.

\begin{tabular}{lccc}
\hline Properties & MEOA $^{\mathrm{a}}$ & HYOOA $^{\mathrm{b}}$ & HYBODA $^{\mathrm{c}}$ \\
\hline Pour point $\left({ }^{\circ} \mathrm{C}\right)$ & -41 & -51 & -43 \\
Flash point $\left({ }^{\circ} \mathrm{C}\right)$ & 128 & 251 & 232 \\
Viscosity index & 130.8 & 153 & 123 \\
Oxidative stability, OT $\left({ }^{\circ} \mathrm{C}\right)$ & 168 & 180.94 & 65 \\
\hline
\end{tabular}

Notes: Monoepoxide linoleic acid (a); 9(12)-hydroxy-10(13)-oleioxy-12(9)octadecanoic acid (b); 9-hydroxy-10-behenoxyoctadecanoic acid [6] (c).

The OT is the temperature at which a rapid increase in the rate of oxidation is observed at a constant, high pressure (200 psi). A high OT would suggest high oxidation stability of the material. OT was calculated from a plot of heat flow $(\mathrm{W} / \mathrm{g})$ versus temperature that was generated by the sample upon degradation and by definition. In this study, using OA for oxirane ring opening of HYOOA significantly improves the oxidation stability of OT for $\mathrm{HYOOA}$ at $180.94^{\circ} \mathrm{C}$ (Figure 7) among others studies such as the OT $65^{\circ} \mathrm{C}$ for the HYBODA [6] (Table 8). The results agree with other studies on synthetic esters, and the OT increased with increasing acyl chain length of the esterified FA [12]. High OT would suggest a high oxidation stability of HYOOA.

\section{Conclusion}

The oxirane ring opening of monoepoxide linoleic acid was done by nucleophilic addition of OA. PTSA shows a high catalytic reactivity that promotes the ring opening reaction and yields a minimum oxirane oxygen content (OOC\%). Overall, physical properties of HYOOA have shown potential in formulation of industrial fluids for different temperature applications.

\section{Acknowledgments}

The authors thank UKM and the Ministry of Science and Technology for research Grant UKM-GUP-NBT-08-27-113 and UKM-OUP-NBT-29-150/2011.

\section{References}

[1] K. Hill, "Fats and oils as oleochemical raw materials," Journal of Oleo Science, vol. 50, pp. 433-444, 2001.

[2] H. Baumann, M. Büehler, H. Fochem, F. Hirsinger, H. Zoebelein, and J. Falbe, "Natural fats and oils-renewable raw materials for the chemical industry," Angewandte Chemie, vol. 27, no. 1, pp. 41-62, 1988.

[3] H. Schuster, L. A. Rios, P. P. Weckes, and W. F. Hoelderich, "Heterogeneous catalysts for the production of new lubricants with unique properties," Applied Catalysis A, vol. 348, no. 2, pp. 266-270, 2008.

[4] Z. Lozada, G. J. Suppes, Y.-C. Tu, and F.-H. Hsieh, "Soy-based polyols from oxirane ring opening by alcoholysis reaction," Journal of Applied Polymer Science, vol. 113, no. 4, pp. 25522560, 2009.

[5] V. Von, Heterogeneously catalyzed reactions with vegetable oils: epoxidation and nucleophilic epoxide ring-opening with alcohols, M.Sc-Chemisch Ingenieur, Universidad de Antioquia, Aus Medellín, Colombia, 2002.
[6] J. Salimon, N. Salih, and E. Yousif, "Chemically modified biolubricant basestocks from epoxidized oleic acid: Improved low temperature properties and oxidative stability," Journal of Saudi Chemical Society, vol. 15, pp. 195-201, 2011.

[7] M. Wu, H. Ding, S. Wang, and S. H. Xu, "Optimization conditions for the purification of linoleic acid from sunflower oil by urea complex fractionation," Journal of the American Oil Chemist' Society, vol. 85, pp. 677-684, 2008.

[8] B. K. Sharma, A. Adhvaryu, Z. Liu, and S. Z. Erhan, "Chemical modification of vegetable oils for lubricants applications," Journal of the American Oil Chemist' Society, vol. 83, pp. 129136, 2006.

[9] H. S. Hwang and S. Z. Erhan, "Modification of epoxidized soybean oil for lubricant formulations with improved oxidative stability and low pour point," Journal of the American Oil Chemists' Society, vol. 78, no. 12, pp. 1179-1184, 2001.

[10] K. M. Doll, B. K. Sharma, and S. Z. Erhan, "Synthesis of branched methyl hydroxy stearates including an ester from bio-based levulinic acid," Industrial and Engineering Chemistry Research, vol. 46, no. 11, pp. 3513-3519, 2007.

[11] B. K. Sharma, K. M. Doll, and S. Z. Erhan, "Ester hydroxy derivatives of methyl oleate: tribological, oxidation and low temperature properties," Bioresource Technology, vol. 99, no. 15, pp. 7333-7340, 2008.

[12] H. Kubouchi, H. Kai, K. Miyashita, and K. Matsuda, "Effects of emulsifiers on the oxidative stability of soybean oil TAG in emulsions," Journal of the American Oil Chemists' Society, vol. 79 , no. 6, pp. 567-570, 2002. 

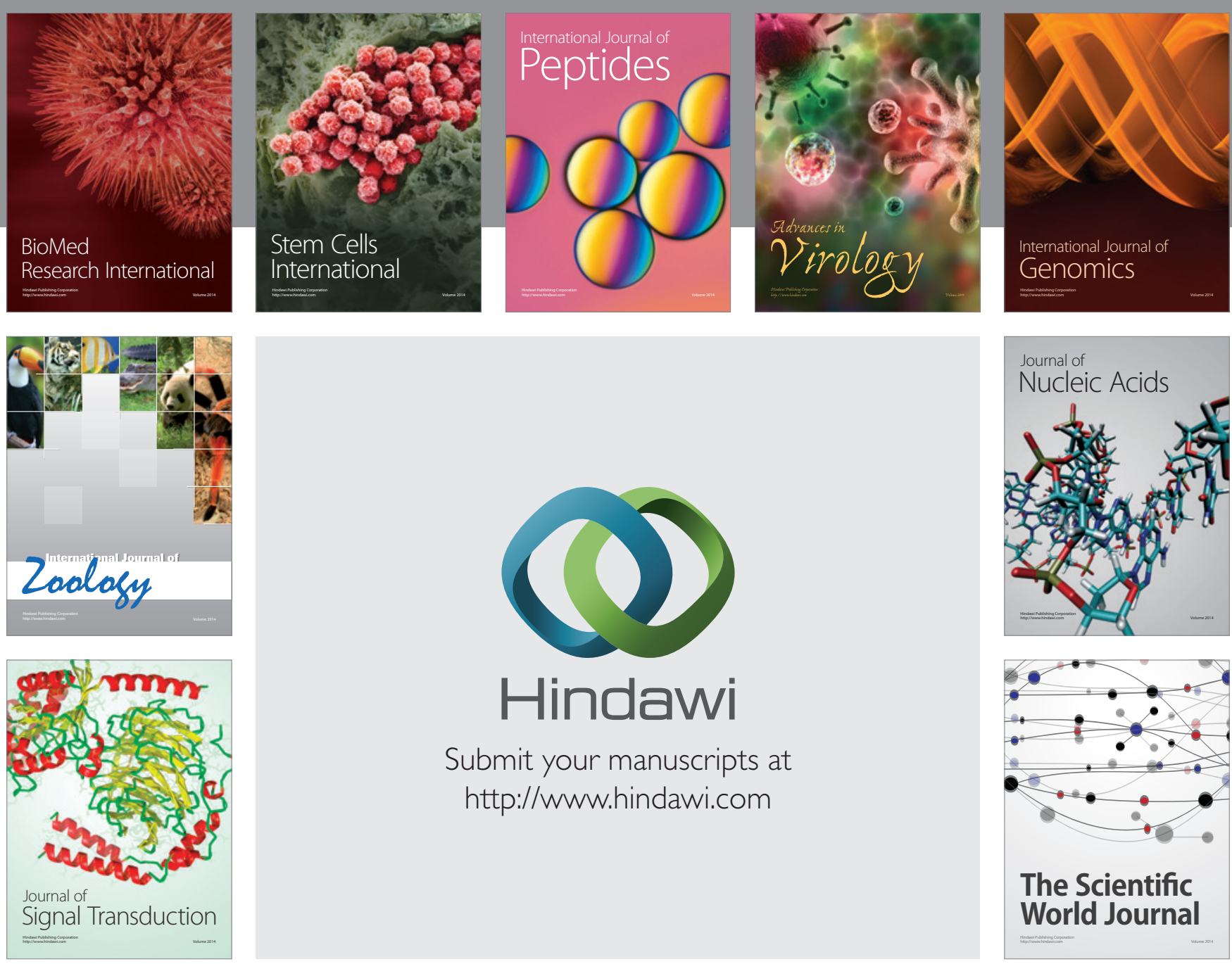

Submit your manuscripts at

http://www.hindawi.com
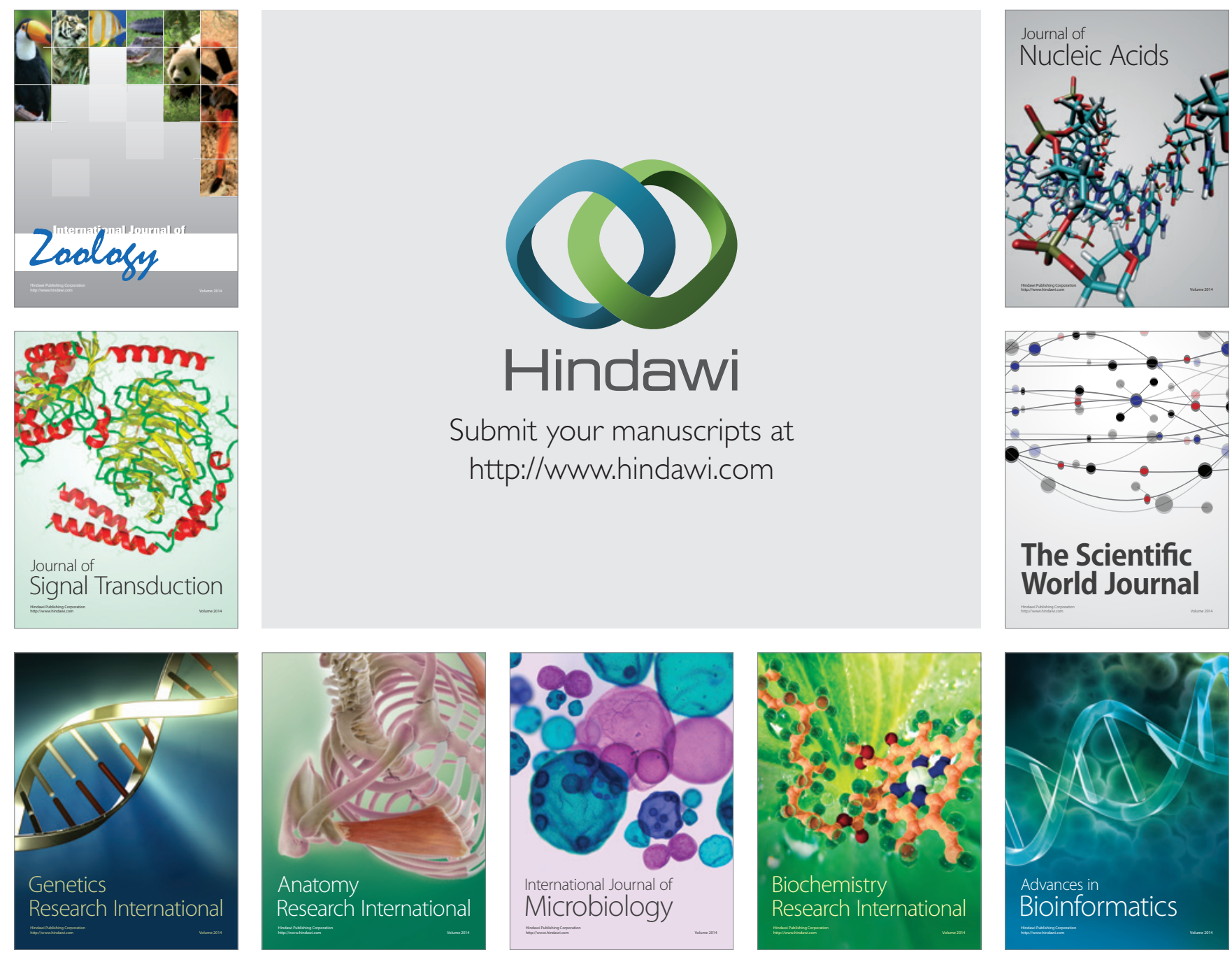

The Scientific World Journal
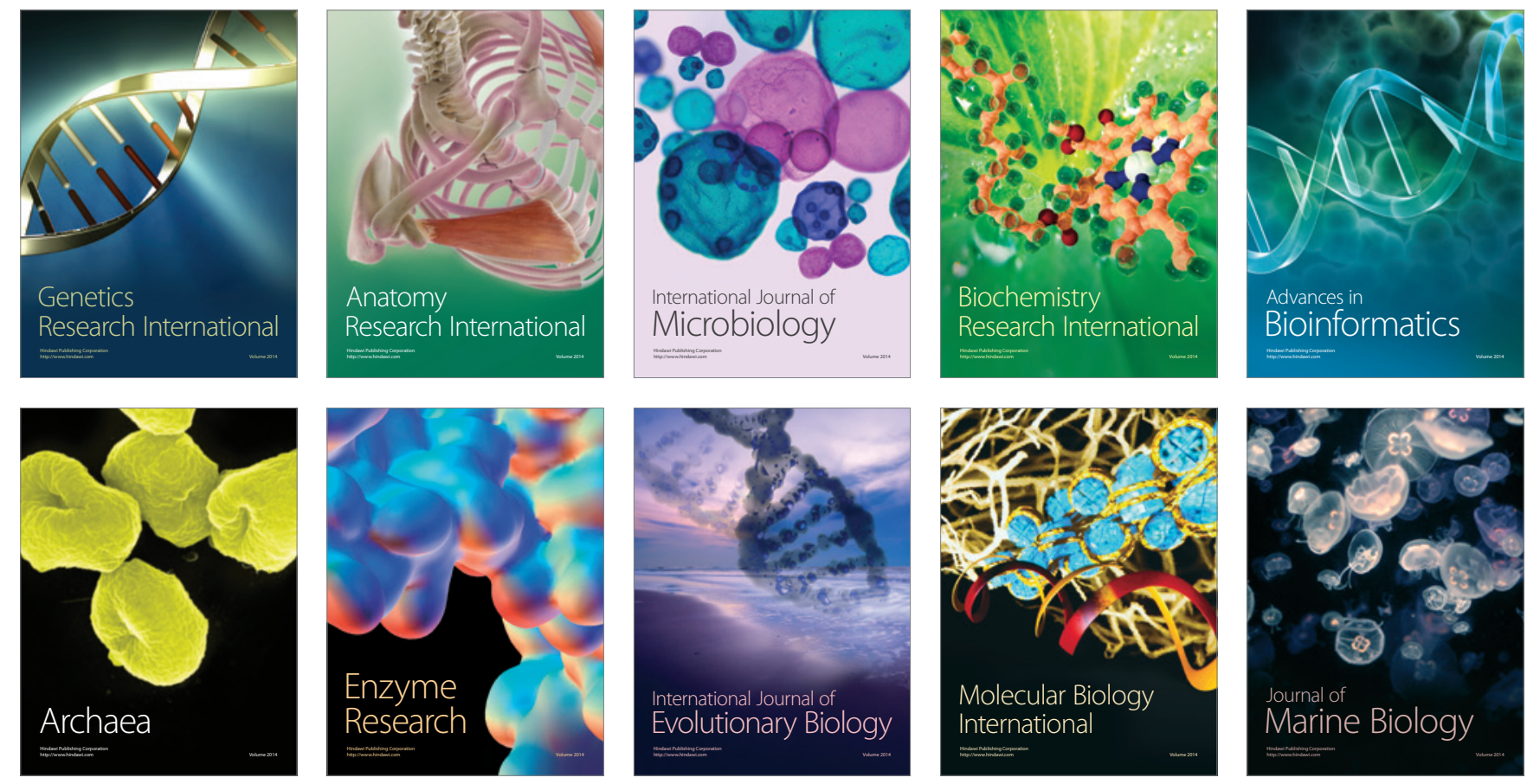